\title{
ASSESSING THE POTENTIAL FOR RADIOCARBON DATING THE SCALES OF AUSTRALIAN LUNGFISH (NEOCERATODUS FORSTERI)
}

\author{
Kelly M James ${ }^{1,2} \cdot$ Stewart J Fallon $^{1} \cdot$ Andrew McDougall $^{3,4} \cdot$ Tom Espinoza $^{3} \cdot$ Craig Broadfoot $^{5}$ \\ ABSTRACT. We present a novel application for radiocarbon dating by aging 4 scales from a single large adult lungfish (Neo- \\ ceratodus forsteri) from the Burnett River, in Queensland, Australia. The relict fish species lack a solid crystalline otolith, \\ which precludes the use of the otolith annuli as a reliable age indicator. Previous attempts to age lungfish using a number of \\ techniques have had only limited success. We report on ages obtained from the dense lamellar bone of the scale, which were \\ isolated from the organic layers that thicken and subsequently obscure the ${ }^{14} \mathrm{C}$ signal. Using the characteristics of the bomb \\ curve, 2 parameter von Bertanalffy growth functions were fit, providing an estimate of absolute age to be $\sim 65-70 \mathrm{yr}$. The \\ information gleaned from this study will aid in assessing the population structure, and therefore management, of this vulner- \\ able species.
}

\section{INTRODUCTION}

Of the once extensive lungfish fauna, there are only 3 genera extant today. They are found exclusively in Africa, South America, and Australia. The Australian lungfish (Figure 1) is found in riverine areas, is largely sedentary, and has by far the smallest geographic distribution of extant species, making it especially vulnerable to land use change and habitat destruction. Remnant populations are found in the Burnett and Mary River systems, South East Queensland (Illidge 1894; Wager 1993), with populations introduced into surrounding systems when the species was thought to be under threat of extinction (O'Connor 1897). The single Australian species, Neoceratodus forsteri, has a rich fossil history that extends to the Cretaceous (Kemp 1986) and is part of a lineage found as far back as the Devonian (Marshall and Schultze 1992). The Australian lungfish (Dipnoi) falls within the class Sarcopterygii, whose subclasses also include the coelacanths (Coelacanthimorpha), the tetrapods and their extinct relatives (Tetrapodomorpha). Molecular evidence suggests the primitive lungfish species was the first to develop adaptations for an amphibious existence 380 Mya (Meyer 1995; Brinkmann et al. 2004). Hence, the Australian lungfish represents the evolutionary link to the first organisms that migrated from sea to land.

The ancestral traits of lungfish are their possession of pectoral and pelvic fins connected by a continuous chain of bones, air-breathing lungs, and distinct evolved cosmoid scales. Evolutionary trends have seen the gradual reduction of the cosmine layer, and although modern representatives are now classified as having elasmoid scales, they still possess a distinct fibrous inner layer of vascular bone set atop a isopedine basal layer of dense lamellar bone (Sire et al. 2009). Concentric growth rings, or circuli, evident on fish scales have historically been used to glean age information, although the accuracy of this aging technique is widely disputed (Campana 2001). Known as a longlived species through captive specimens, attempts to obtain precise age estimations have been hampered by the lack of discrete annuli in a solid crystalline otolith as a reliable age indicator (Gauldie et al. 1986; Brooks and Kind 2002). Mark and recapture experiments in the field have been unable to validate visual scale estimates (Brooks and Kind 2002). While lungfish scales did exhibit scale

\footnotetext{
${ }^{1}$ Research School of Earth Sciences, Australian National University, Canberra ACT, Australia.

${ }^{2}$ Corresponding author. Email: kelly.james@anu.edu.au.

${ }^{3}$ Department of Environment and Resource Management, Bundaberg QLD, Australia.

${ }^{4}$ PO Box 1544, Broome, WA 6725, Australia.

${ }^{5}$ Department of Primary Industries and Fisheries, Bundaberg QLD Australia.
}

(C) 2010 by the Arizona Board of Regents on behalf of the University of Arizona Proceedings of the 20th International Radiocarbon Conference, edited by A J T Jull RADIOCARBON, Vol 52, Nr 2-3, 2010, p 1084-1089 


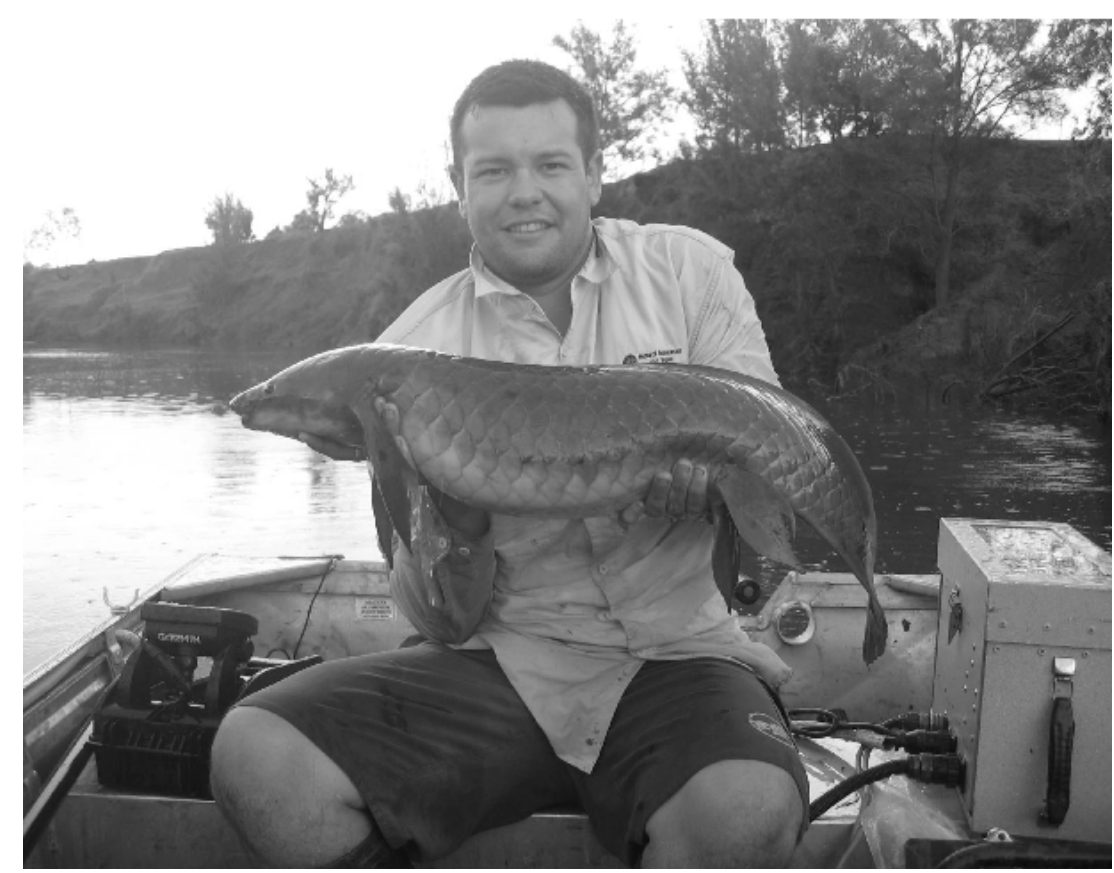

Figure 1 Adult Australian lungfish, Neoceratodus forsteri (image courtesy of T Espinoza)

incremental structure, the periodicity of increment deposition and resolution of the chemical tag was difficult to interpret.

Age estimation is an extremely important biological variable as it underpins the understanding of population dynamics through the validation of growth and mortality rates, and productivity (Campana 2001). In this study, we utilize the pulse of radiocarbon, produced by atmospheric nuclear weapons testing, incorporated into the scale structure to determine the lifespan of an individual lungfish. This study marks the first attempt to use ${ }^{14} \mathrm{C}$ to address the dearth of information regarding the growth patterns and longevity of this vulnerable relict species.

\section{METHODS}

\section{Sampling}

In this study, 4 scales were obtained from a single individual (1250 $\mathrm{mm}$ length) found deceased in the Burnett River, Queensland, Australia, 2008. Undamaged whole scales were removed from both ventral and lateral sides of the fish and weighted down to dry. Agreement was reached between 2 scale readers as to the position of the primordium (origin of growth), and was marked on scanned images of each respective scale. A Dremel ${ }^{\circledR}$ drill was used along the growth axis, isolating the dense lamellar bone from the possible overprint of the organic protein layer. Once a uniform thickness was obtained, the sample was subjected to a weak $\mathrm{NaOH}$ clean and Milli-Q rinse; possible modifications to this method are addressed below. While pliable, a scalpel was used to slice along transverse grooves as thinly as possible to achieve an end sample size $\sim 0.5 \mathrm{~mm}$ in width and approximating $\sim 1-1.5 \mathrm{mg}$ dry weight. Samples were placed in clean 6-mm-diameter quartz tubes with $\mathrm{CuO}$ and $\mathrm{Ag}$ wire, and then combusted at $900{ }^{\circ} \mathrm{C}$ for $4 \mathrm{hr}$. Conversion to graphite was achieved in the presence of Fe powder and $\mathrm{H}_{2}$ gas (water being removed during reaction with $\left.\mathrm{Mg}\left(\mathrm{ClO}_{4}\right)_{2}\right)$. Samples were run on 
the single stage accelerator mass spectrometer (SSAMS) at the Research School of Earth Sciences, The Australian National University.

\section{Age and Growth Analysis}

As a first approximation of age and growth rate, pMC (percent modern carbon) was plotted against distance from the outer edge (Figure 2). From the first scale, a total of 36 subsamples were taken from the outer edge to the primordium to ascertain the position and existence of a bomb signal. From the "bomb" curve, tie points to the years 1955 (inflection of curve), 1966 (peak of weapons testing) and 2008 (date of capture) were ascertained. A von Bertalanffy growth function (VBGF) was then adapted using the following equation (von Bertalanffy 1938):

$$
L(t)=L_{\infty}\left(1-\mathrm{e}^{-k\left(t-t_{0}\right)}\right)
$$

where $L(t)$ is total length along growth axis at time $t$ (age in yr), $L_{\infty}$ the maximum length, $k$ the growth constant that describes the initial slope and $t_{0}$ the theoretical year at zero length. The growth model parameters were generated using a Solver based spreadsheet in Microsoft Excel ${ }^{\circledR}$.

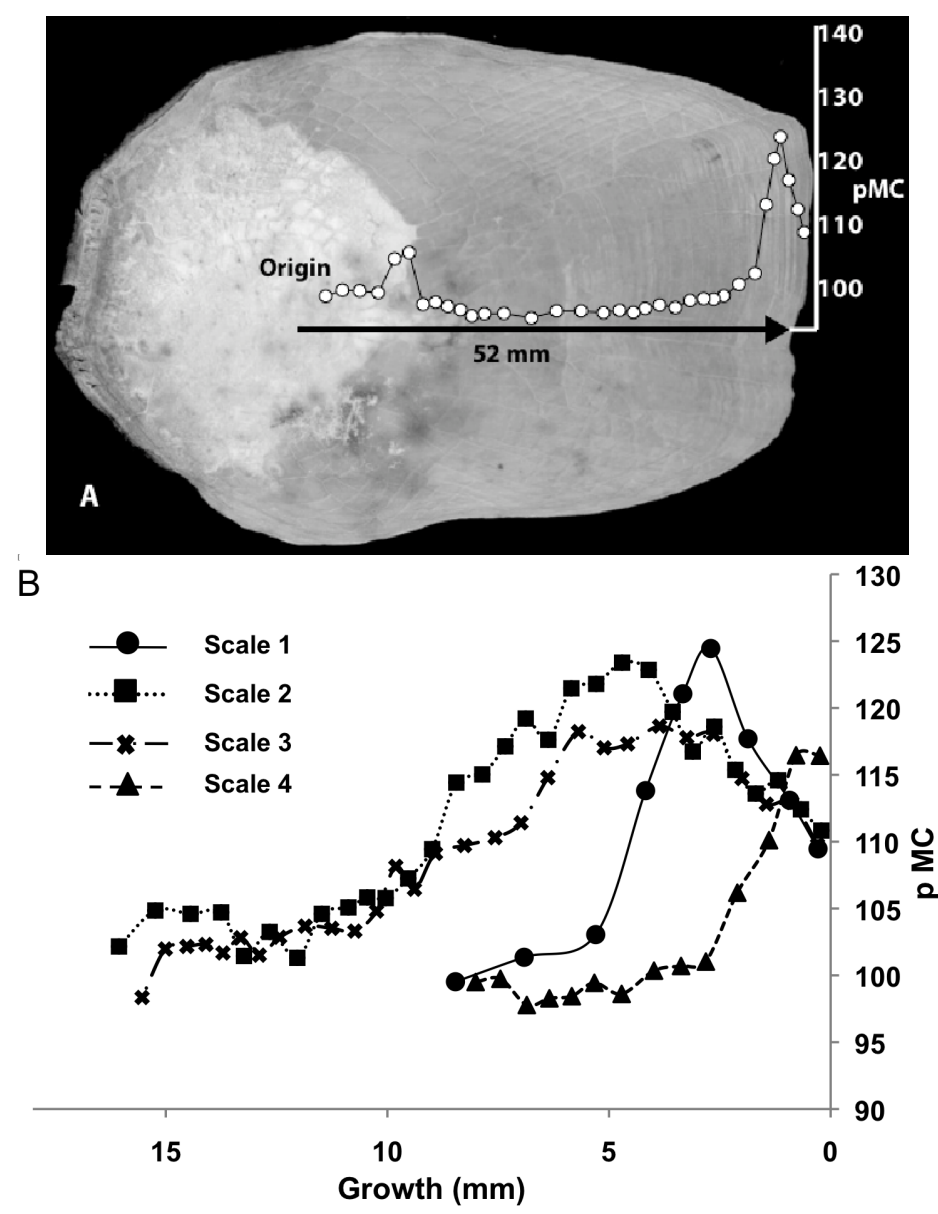

Figure 2 A) pMC as sampled over the entire growth axis of scale $1(n=36)$. B) pMC as a function of distance (Scales 1-4) from the distal margin. 


\section{RESULTS}

The model predicted the year at 0 length, or birth, for this specimen to fall between 1940 and 1946 ( \pm 2 yr) (Figure 3 ). There is good agreement between scales 1-3 for all parameters, indicating the absence of regenerated scales that could underestimate absolute age (Table 1). Scale 4 was obtained from along the dorsal edge of the fish thought representative of the earliest forming scales (A Kemp, personal communication). Sampling from the distal edge revealed a maximum value of $116 \mathrm{pMC}$. The minimal accretion of new material on a small scale in such a long-lived individual was found to be beyond detection at the sampling resolution undertaken $(\sim 0.5 \mathrm{~mm})$. As we were unable to ascertain the peak of the bomb curve for this scale, it was not included in growth analysis.

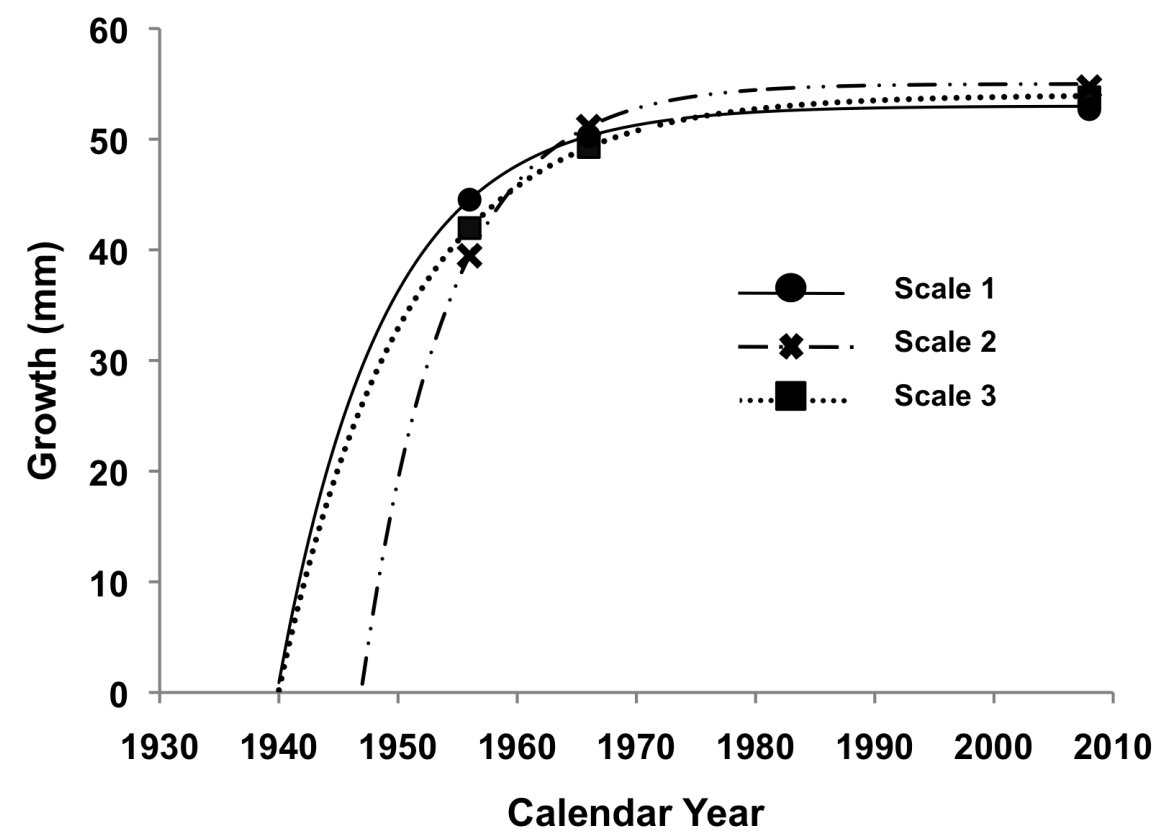

Figure 3 VBGF for scales 1-3 plotted against calendar year

Table 1 VBGF parameters and distance from margin $(\mathrm{mm})$ to reach theoretical 1955.

\begin{tabular}{lllll}
\hline Scale & $L_{\infty}$ & $k$ & $t_{0}$ & Distance $(\mathrm{mm})$ \\
\hline 1 & 53 & 0.114 & 1940 & 8.47 \\
2 & 55 & 0.139 & 1947 & 15.54 \\
3 & 54 & 0.094 & 1940 & 12.03 \\
4 & 28 & & & 8.01 \\
\hline
\end{tabular}

From Figure 3, it can be seen that scale growth rates are highest for the first 15-20 yr. Indeed, the fitted curve indicates over $30 \mathrm{~mm}$ of scale growth within the first $10 \mathrm{yr}$, with the horizontal asymptote of the VBGF curve $(\sim 52 \mathrm{~mm})$ being reached within $30 \mathrm{yr}$. A mere $4-5 \mathrm{~mm}$ of scale growth is predicted to have occurred after this time, spanning an estimated period of almost $40 \mathrm{yr}$. Between the 1956-1966 period of interest, sampling $\sim 0.5$-mm increments will resolve 1-2 yr of growth. This resolution is drastically decreased toward the distal margin of the scale where a $0.5-\mathrm{mm}$ sample is more likely to encapsulate $20 \mathrm{yr}$ of growth, and concomitant ${ }^{14} \mathrm{C}$ signal. 


\section{DISCUSSION}

Bomb ${ }^{14} \mathrm{C}$ dating has proven a highly effective means of validating the periodicity of growth increments in fish otoliths, enabling the determination of absolute age in many studies (Campana 2001; Davis-Foust et al. 2009; McPhie and Campana 2009). Scalimetry, or scale reading, is an alternate method of obtaining age information and has been described as the trade-off between accuracy and conservation imperatives due to the non-lethal means of obtaining the structure for analysis (Danancher et al. 2007). However, the element of subjectivity during scale reading can lead to substantial interpretive error (Campana 2001). This is particularly the case toward the distal margin of the scale where compression and crowding can confound accurate estimation. Utilizing the bomb curve incorporated within the scale structure gives the advantage of eliminating much subjectivity (except for determining the position of the primordium) while still allowing a first estimate of longevity and growth patterns. Our results show that resolution using bomb ${ }^{14} \mathrm{C}$ analysis in scales is sufficient to glean the tie points needed for growth model input.

The peak signal incorporated within the structure (112-124 pMC) is considerably dampened compared to the calibration curve of the Tasmanian pine (peak $165 \mathrm{pMC}$ ) used for the Southern Hemisphere ${ }^{14} \mathrm{C}$ calibration for this study (Hua et al. 2000). A possible explanation for this is that the $\mathrm{pMC}$ is a reflection of habitat and trophic position of the lungfish. The Australian lungfish is not an obligate aerobe, only using its well-developed air-breathing lungs during times of exertion or when water quality is particularly low (Kemp 1986). This also enables foraging within the muddy substrate for food sources. While the water depth of the lungfish habitat facilitates rapid exchange with the atmosphere, the turbidity of the water increases during seasonal flooding events. Mobilized sand and silt in the water column could result in increased consumption, and therefore overprinting, of sedimentary or dietary carbon. The lungfish diet changes as it develops, beginning with worms or small crustacea found in riverine sediments, supplemented with filamentous algae (Kemp 1986). Adults are also known to ingest aquatic macrophytes for the animal food attached, the macrophytes themselves remaining largely undigested. It is important to note that the exact mechanisms by which carbon is incorporated within the dense lamellar bone of the fish scale is not entirely clear, although the primary source is through dietary metabolism rather than the surrounding water (McPhie and Campana 2009).

Alternately, although utmost care was taken to remove the proteinaceous material that grows in the adjacent direction to the extending scale, contamination could also be responsible for the observed offset. Indeed, a marked increase in pMC was observed in samples taken directly over the section that anchors the scale within the dermal layer (Figure 2). Modifications to sample preparations for future work could include a bleaching step to aid the removal of organic material, and a final $\mathrm{HCl}$ and Milli-Q rinse to hinder the absorption of ambient $\mathrm{CO}_{2}$ after the alkali wash. For a bomb ${ }^{14} \mathrm{C}$ chronology to be a robust tool for age estimation, the shape of the curve, rather than the amplitude, is of greater significance. As a test, substituting earlier capture dates of 1990 and 1980 into our equation for scale 1 and solving for $t_{0}$, results in a slight underestimate of age: 1943 and 1944, respectively, from a calculated $t_{0}$ of 1940 . This demonstrates the robustness of this parameter, and the validity of including archived scales when date of capture is somewhat uncertain. Several hundred scales were collected during the previous work of Brooks and Kind (2002), providing an excellent scale archive that negates the need to collect further samples from this important species. In their study, approximately 1500 lungfish were also marked with a chemical tag between 1998 and 2000, with these individuals now being at liberty for $\sim 10 \mathrm{yr}$. Recapture of these individuals and analysis of their scales will provide improved resolution in the incremental deposition rate on the outer margins of adult lungfish scales. This will ultimately lead to a more accurate age estimate for lungfish cohorts and improved understanding of lungfish population dynamics. 


\section{CONCLUSION}

Although the resolving power of this method limits its application to absolute age rather than the validation of growth increments, the current study has provided the first age approximation for an individual lungfish. This study demonstrates a novel use of ${ }^{14} \mathrm{C}$ dating and its application in the conservation of a vulnerable and long-lived species. Future work could potentially correlate scale reading and extension rates, and provide ecologists with a non-lethal means of assessing population dynamics. A much larger data set is required to confidently describe the biological parameters needed for management models that will ultimately protect this "living fossil."

\section{ACKNOWLEDGMENTS}

The authors wish to thank Nancy Beavan Athfield and an anonymous reviewer for their help evaluating this paper. Kelly M James was supported in part by the Hales Scholarship, awarded by the Research School of Earth Sciences, The Australian National University.

\section{REFERENCES}

Brinkmann H, Denk A, Zitzler J, Joss JJ, Meyer A. 2004. Complete mitochondrial genome sequences of the South American and the Australian lungfish: testing of the phylogenetic performance of mitochondrial data sets for phylogenetic problems in tetrapod relationships. Journal of Molecular Evolution 59(6):834 48.

Brooks SG, Kind PK. 2002. Ecology and demography of the Queensland lungfish (Neoceratodus forsteri) in the Burnett River, Queensland with reference to the impacts of Walla Weir and future water infrastructure development. Queensland Department of Primary Industries. Queensland: Queensland Agency for Food and Fibre Services.

Campana SE. 2001. Accuracy, precision and quality control in age determination, including a review of the use and abuse of age validation methods. Journal of Fish Biology 59(2):197-242.

Danancher D, Labonne J, Gaudin P, Joly P. 2007. Scale measurements as a conservation tool in endangered Zingel asper (Linnaeus 1758). Aquatic Conservation: Marine and Freshwater Ecosystems 17(7):712-23.

Davis-Foust SL, Bruch RM, Campana SE, Olynyk RP, Janssen J. 2009. Age validation of freshwater drum using bomb radiocarbon. Transactions of the American Fisheries Society 138:385-96.

Gauldie RW, Dunlop D, Tse J. 1986. The remarkable lungfish otolith. New Zealand Journal of Marine and Freshwater Research 20:81-92.

Hua Q, Barbetti M, Jacobsen GE, Zoppi U, Lawson EM. 2000. Bomb radiocarbon in annual tree rings from Thailand and Tasmania. Nuclear Instruments and Methods in Physics Research B 172(1-4):359-65.
Illidge T. 1894. Report to the Royal Society of Queensland. Proceedings of the Royal Society of Queensland 10:41-4.

Kemp A. 1986. The biology of the Australian lungfish, Necteratodus forsteri (Krefft, 1870). Journal of Morphology Supplement 1:181-98.

Marshall C, Schultze HP. 1992. Relative importance of molecular, neontological, and paleontological data in understanding the biology of the vertabrate invasion of land. Journal of Molecular Evolution 35(2):93101.

McPhie RP, Campana SE. 2009. Bomb dating and age determination of skates (family Rajidae) off the eastern coast of Canada. ICES Journal of Marine Science 66(3):546-60.

Meyer A. 1995. Molecular evidence on the origin of tetrapods and the relationships of the coelacanth. Trends in Ecology \& Evolution 10(3):111-16.

O'Connor D. 1897. Report on preservation of Ceratodus. Proceedings of the Royal Society of Queensland 12: 101-2.

Sire J-Y, Donoghue PCJ, Vickaryous MK. 2009. Origin and evolution of the integumentary skeleton in nontetrapod vertebrates. Journal of Anatomy 214(4):40940.

von Bertalanffy L. 1938. A quantitative theory of organic growth (Inquiries on growth laws II). Human Biology 10:181-213.

Wager RNE. 1993. The Distribution and Conservation Status of Queensland Freshwater Fishes. Queensland Department of Primary Industries Information Series No Q193001. 